\title{
¿HISTORIAR ES NARRAR?
}

\author{
Pere Solà Gussinyer ${ }^{1}$ \\ Universidad Autónoma de Barcelona \\ pere.sola@uab.cat
}

\section{RESUMEN}

El autor del artículo reflexiona sobre su conversión del resultado de su investigación sobre la vida, el ideario y la obra de un pedagogo catalán de referencia internacional y de trágico final en una propuesta narrativa de ficción. Así, saca partido a las lecciones de una experiencia vital durante el severo confinamiento en una urbe como Barcelona (pero que podría ser cualquier conurbación del ancho mundo) por la pandemia, para mostrarnos hasta qué punto la "verdad histórica" y el "sentido profundo" de un pasado que nos interpela pueden ser potenciados por la narrativa de fícción, más allá de la hojarasca teórica y el andamiaje documental de la producción académica ordinaria.

Palabras clave: Historia de la educación y narratividad. Francesc Ferrer Guàrdia. Escuela Moderna.

\section{HISTORIAR É NARRAR?}

\section{RESUMO}

O autor do artigo reflete sobre a conversão do resultado de sua pesquisa sobre a vida, as ideias e a obra de um pedagogo catalão de referência internacional e fim trágico em uma proposta narrativa ficcional. Assim, ele aproveita as lições de uma experiência vital durante o severo confinamento em uma cidade como Barcelona (mas que poderia ser qualquer conurbação no vasto mundo) pela pandemia, para nos mostrar em que medida a "verdade histórica" e o "sentido profundo", de um passado que nos desafia, podem ser potencializados pela narrativa ficcional, para além da verbosidade teórica e do alicerce documental da produção acadêmica ordinária.

Palavras-chave: História da educação e narratividade. Francisco Ferrer Guardia. Escola Moderna.

\section{IS HISTORICIZING JUST NARRATING?}

\begin{abstract}
The author of the paper reflects on his conversion of the result of his research on the life, thought and work of a Catalan pedagogue of international reference and tragic ending, into a narrative proposal of fiction. Thus, it takes advantage of the lessons of a vital experience during the severe confinement in a city like Barcelona (but that could be any conurbation of the wide world) by the pandemic, to show us the extent to which the "historical truth" and the "deep sense" of a past that
\end{abstract}

\footnotetext{
${ }^{1}$ Catedrático Emérito de Historia de la Educación en la Universidad Autónoma de Barcelona.
} 
challenges us can be enhanced by the fictional narrative, beyond the theoretical leafy and documentary scaffolding of ordinary academic production.

Keywords: History of education and narrativity. Francesc Ferrer Guàrdia. Modern School.

\section{HISTOIRE EST NARRATION?}

\section{RÉSUMÉ}

L'auteur de l'article réfléchit à sa conversion du résultat de ses recherches sur la vie, les idées et l'œuvre d'un pédagogue catalan de référence internationale et de fin tragique en une proposition narrative fictive. Ainsi, il profite des leçons d'une expérience vitale lors de l'enfermement sévère dans une ville comme Barcelone (mais qui pourrait être n'importe quelle agglomération dans le vaste monde) par la pandémie, pour nous montrer à quel point la «vérité historique» et la La "signification profonde" d'un passé qui nous interpelle peut être renforcée par un récit fictif, audelà des déchets théoriques et de l'échafaudage documentaire de la production académique ordinaire.

Mots clès: Histoire de léducation et narrativité. Francisco Ferrer Guardia. École Moderne.

\section{INTRODUCCION}

Este artículo propone una reflexión sobre un experimento epistemológico/literario reciente de su autor. A saber, la conversión de una biografía histórica -basada en la investigación sobre la vida, el ideario y la obra de un pedagogo ibérico de referencia internacional y de trágico final- en una propuesta narrativa de ficción.

\section{ESTUDIO DE CASO DE UN EXPERIMENTO}

De este "experimento" ha salido una "novela histórica", que se puede considerar legítimamente un fruto o producto de lo personalmente vivido durante el severo confinamiento en una urbe como Barcelona (pero que podría ser cualquier conurbación del ancho mundo) por la pandemia.

El objetivo principal de esta contribución es analizar, a través de un estudio de caso, hasta qué punto la "verdad histórica" y el "sentido profundo" de un pasado que nos interpela pueden ser potenciados por la narrativa de ficción, más allá de la hojarasca teórica y el andamiaje documental de la producción académica ordinaria. 
Agradezco a la publicación RIDPHE_R, Revista Iberoamericana del Patrimonio HistóricoEducativo, y concretamente a la investigadora doctora Maria Cristina Menezes, la amabilidad de haberme invitado a este ejercicio historiográfico/literario.

Como se ha dicho, durante el drástico confinamiento sufrido a causa de la pandemia del Covid-19, en la pasada primavera, el autor de este artículo puso a punto una novela biográfica actualmente en curso de publicación (SOLÀ GUSSINYER, 2020-2021). En ella convirtió, o menor dicho vertió, derramó o tradujo una parte de su investigación sobre la vida, el ideario y la obra de un pedagogo catalán de referencia internacional y de trágico final en una propuesta narrativa de ficción.

Concretamente se basó en su estudio inédito "Francisco Ferrer Guardia, activista social y mártir de la educación libre” (Barcelona, 2018), de 280.000 palabras, cerca de 500 páginas y 800 notas documentales. Transformó los datos de dicha investigación en un relato donde el personaje protagonista se expresa en primera persona.

Al respecto, se permitió añadir algunos pasajes inventados, pero debidamente contextualizados, para agilizar la lectura de la novela histórica "sui géneris" que iba surgiendo.

Siguió, en parte, la técnica que la crítica literaria ha dado en denominar "stream of consciousness", técnica consistente en verter (en la forma más o menos ordenada en que se van sucediendo) los pensamientos, sensaciones, impresiones y sentimientos que pasan por la cabeza de un personaje, el narrador en primera persona ${ }^{2}$.

La novela en cuestión consiste en un dietario o diario de cárcel, redactado a lo largo de septiembre y las dos primeras semanas de octubre de 1909. Es la crónica de una muerte anunciada, de una muerte a manos de las "fuerzas reaccionarias" del mundo en que vive el personaje.

¿Podría él haber cambiado su destino? Por ejemplo. renegando o escondiendo sus convicciones y rehuyendo sus responsabilidades?

El protagonista autor de estas notas autógrafas de cárcel es un pedagogo y editor racionalista de éxito, muy conectado al movimiento sindical, librepensador, anarquista y republicano europeo del momento anterior a la gran guerra mundial de 1914-1918. Explica su intento infructuoso de

\footnotetext{
${ }^{2}$ Desde su identificación teórica por Alexander Bain (1855) y William James (1890), reputados autores como Marcel Proust, James Joyce o Virginia Woolf han recurrido al género de la "corriente de conciencia". Pero el género de la narración en primera persona viene de lejos, basta con recordar el clásico anónimo castellano del Siglo de Oro El lazarillo de Tormes o fragmentos antológicos de la novela Pedro Páramo de Juan Rulfo.
} 
sortear la persecución de las autoridades de la monarquía, que le acusan de haber sido el organizador de una huelga general revolucionaria en Cataluña de una semana, acompañada de incendios contra instalaciones religiosas (católicas) y proclamas republicanas.

Se oculta primero en un escondrijo de su casa. Ahora bien: el cerco sobre él se va estrechando y decide huir. Pero, en el intento, es detenido de noche por una especie de guardia cívica, de voluntarios, para gran regocijo de todo el establishment monárquico. La presa, sin embargo, no es un cualquiera.

Se trata de un personaje público muy conocido, dentro y fuera de las fronteras. Mucho de su vida ha sido divulgado por la prensa, pero hay aspectos secretos de su vida que nadie sabe. En la cárcel -primero en la nueva y moderna prisión panóptica del centro de la capital, y los últimos tres días en la fortaleza/castillo militar que la preside- el autor del cuaderno de celda rememora su vida, desde la infancia, su familia, su paso por la escuela, su iniciación a la vida laboral y sus primeros escarceos en la militancia política.

Va pasando revista a los grandes temas y momentos de su existencia, ahora que ve a ésta en peligro mortal inminente. Pero la esperanza es lo último que se pierde, y nuestro protagonista no abandona del todo la fe en la posibilidad de un indulto "in extremis". Va rememorando su juventud autodidacta. su fracaso familiar. Su matrimonio roto. Su difícil relación sentimental con las mujeres. La vida de sus hijas y nietos, que no ve crecer. Pero, sobre todo, evoca sus logros como editor popular y como impulsor de movimientos sociales.

Afronta serenamente, por lo menos en apariencia, su más que probable fin, pero denuncia la tortura psicológica a que está sometido. Dedica parte de sus últimas energías a pensar a fondo sus últimas voluntades testamentarias.

La novela presenta un personaje de carne y huesos. Muy alejado del "mito" que ha llevado sea a la sacralización sea a la demonización que sobre él se ha ido construyendo, y del que el mismo revisionismo historiográfico de las últimas décadas no es ajeno. Un personaje de carne y hueso no exento de grandes contradicciones.

En el caso de este ensayo de novela acerca de la trayectoria del pedagogo ibérico racionalista asesinado legalmente en 1909 se imponía transitar por un campo minado, cosa que equivale a deconstruir y resignificar zonas de una vida "para los otros", campos o ítems tales como: 
1. Aprendizaje personal, autoaprendizaje

2. Educación sentimental

3. Relación con el otro sexo

4. Trato con familia $y$ amigos

5. Destino, fortuna $y$ trayectoria de familiares descendientes

6. Compromiso político

7. Masonería

8. Laicismo y anticlericalismo

9. Las amistades peligrosas

10. Capacitación pedagógica: modelos

11. Educación e ideología

12. Ciencia, razón

13. Idioma escolar vehicular

14. Extensión escolar

15. Proyecto editorial

16. Lucha de clases

17. La emancipación colonial
19. Identidad nacional

20. Violencia revolucionaria

21. Comunismo libertario

22. Republicanismo radical

23. La institución monárquica

24. Arte y cambio social

25. La religión confesional

26. Derechos humanos

27. Derecho a la vida $y$ pena de muerte

28. Lecturas pedagógicas posteriores: memoria histórica en educación

29. La polémica historiográfica en torno al honor de los estados

30. Los juicios de valor morales o de valía humana y cultural

31. Crítica de las fuentes

32. Historia y mito

33. La propia ideología y el propio punto de vista del narrador de historias como horizonte o límite

18. La institución armada

Fuente: autor.

Todos estos ítems van surgiendo en la novela, sea a través del diálogo i/ o los espacios de "corriente de consciencia" del protagonista, a veces trufada con extractos documentales reveladores, sea a través de los apuntes editoriales del narrador de la novela histórica.

Por ejemplo, poco se sabe de la música en la Escuela Moderna. Pero es evidente que se impartía con regularidad mientras funcionó, mediante hasta tres sesiones semanales de una hora de solfeo en los niveles -párvulos, elemental y superior. En este curso el profesor de música D. Adrián 
Esquerrá y Codina impartía dos horas a la semana. Este era, a toda luz por encargo, el autor de los cánticos escolares en la escuela impulsada por el biografiado. Consta que el contenido de dichas canciones fue uno de los elementos aducidos por las autoridades monárquicas para impedir su reapertura a partir de cierto momento. El compositor tuvo que declarar en el juicio por intento de regicidio. Un extracto documental incriminatorio, asociando a la música:

Extracto "La Subsecretaría acordó que el Inspector provincial de $1^{a}$ enseñanza de [plaza] emitiese dictamen en cumplimiento del R.D. $1^{\circ}$ de julio de 1902- "El Inspector informa que, aunque algo inadecuado con relación al objeto a que se destina el local propuesto para instalar [esta escuela], reúne condiciones de seguridad, decoro e higiene, que el establecimiento que se proyecta es una continuación modificada en cuanto a ciertos libros de texto de la escuela racionalista que venía dirigiendo [el director de la escuela] en el mismo edificio y piso, que algunos de los libros que se proponen sustentan doctrinas morales perniciosas y otros carecen de forma y método verdaderamente pedagógicos. El Negociado correspondiente del Ministerio manifiesta que ha examinado con toda escrupulosidad los datos y documentos aportados a este expediente, de los que resulta que algunos de los libros adoptados para la enseñanza, sobre ser de escaso valor pedagógico, contienen principios peligrosos para la moral y que los cantos escolares que se enseñan a los niños son subversivos del orden social, conteniendo gravísimos ataques a la Patria, al Ejército y a la Religión. Que por estos motivos entiende que debe negarse la autorización solicitada pues el caso de [la escuela en cuestión] se halla evidentemente comprendido dentro de los en que el Estado, ejerciendo su acción tutelar de inspección por lo que a la moral y a los principios del régimen social en que vivimos se refiere, no puede ni debe autorizar la enseñanza ni la propaganda de doctrinas tan perniciosas como las contenidas en los libros y carteles que figuran unidos al expediente. Que, como se trata, sin embargo, de una medida que ha de servir de precedente y sentar jurisprudencia en materia tan delicada como la del ejercicio de la enseñanza, propone que pase el expediente al Consejo de I.P., a fin de que la resolución que se dicte salga revestida de toda la autoridad exigible a la Administración pública.

La Sección y la Subsecretaría se adhieren al Dictamen del Negociado y el expediente pasa al Consejo. Los libros y folletos a que se alude y acompañan al expediente consisten en una "cartilla filológica española", en cuya página 59 se lee:

"Los desgraciados que en los presidios practican el taraceo, lo mismo que los salvajes en sus selvas, sólo se taracean la epidermis. Los personajes civilizados que se creen por derecho propio directores de la humanidad -jsi serán imbéciles!también se taracean, no en la carne sino en las levitas y en los casacones. Todas las condecoraciones, insignias heráldicas, medallas y escapularios son puro taraceo";

y varios cantos escolares con letra y música, figurando en el titulado "Los juguetes" el siguiente verso:

"Poned en duda todo misterio que no se explique por el Maestro, negad en firme todos los cuentos de los teólogos y de los clérigos -os interrumpen en las

Rev. Iberoam. Patrim. Histórico-Educativo, Campinas (SP), v. 7, p. 1-21, e021003, 2021. 
lecciones, ya las campanas, ya los tambores, ya las cornetas, ya los cañones, hacen más ruido, los más innobles"; y en el llamado "El Día":

"Oh! patriotismo, negra falsedad, fuente y origen de la autoridad, de insano germen cual la propiedad nace solamente la desigualdad".

Denegada la apertura por R.O. Fecha; 20 de agosto de 1909".]

En la novela el profesor de música y su relación con el director de la polémica escuela es evocado en los términos siguientes:

\section{Cançons de guerra}

El nostre professor de solfeig per a tots els infants era deixeble d'Enric Morera, sí, el de la sarsuela La Santa Espina, que es va estrenar el gener de 1907 al Teatre Principal, mentre jo m'estava barallant amb els jutges a la Model de Madrid. Ell també era i és molt de la ceba; va fer, per exemple una versió en sardana dels Segadors. Fins feia poc havia estat sotsdirector de la societat de cants de Clavé Catalunya Nova. Era molt entusiasta d'una música popular que connectés amb el món obrer.

Encara recordo aquell migdia de primavera primerenca, amb un vent viu que s'emportava literalment els rams tan ben agençats de les floristes. Feia pocs mesos que havia mort el poeta Verdaguer. Doncs bé, em vaig trobar, amb el professor de música, per la Rambla. Sí home, aquell que venia a ensenyar solfeig i cant a la nostra escola una hora dos cops per setmana. La cosa va anar així... Jo venia d'una reunió als Quatre Gats amb els redactors de la meva revista obrera. Anava tot encaboriat immers en els meus pensaments. I no em vaig adonar que des de Canaletes baixava, pel meu tros de vianants i a tota pastilla, un galifardeu ciclista amb un gran cistell ple de flors al portafarcells.

\section{Canciones de guerra}

Nuestro maestro de solfeo para todos los niños era discípulo de Enric Morera, sí, el de la zarzuela La Santa Espina, la que se estrenó en enero de 1907 en el Teatro Principal, mientras yo me estaba peleando con los jueces en la Modelo de Madrid. También era y es muy "de la cebolla" [ultra-nacionalista, término entre irónico y peyorativo]; hizo, por ejemplo, una versión sardana de Els Segadores [Himno de Cataluña]. Hasta hace poco había sido subdirector de la sociedad de canto de Clavé Catalunya Nova. Estaba muy entusiasmado con el cultivo de un tipo de música popular que conectara con la clase obrera.

Todavía recuerdo aquel mediodía de temprana primavera, con un viento animado que, literalmente, tomaba los ramos tan delicadamente dispuestos de las floristas. El poeta Verdaguer había muerto hace unos meses.

Bueno, el caso es que dimos con profesor de música en Las Ramblas. Sí, hombre..., aquel que impartía clases de música en nuestra escuela una vez a la semana.

La cosa fue así... Yo regresaba de una reunión en el café llamado Quatre Gats con los editores de nuestra revista a favor de la huelga general. Andaba totalmente inmerso en mis pensamientos, de modo 
Sort d'un noi que em va apartar al moment precís perquè altrament el xoc amb el transportista hagués pogut ser de campionat i ben preocupant, no en tingueu cap dubte, per a la meva integritat física!

De seguida em vaig adonar que el que m'havia dit: "ull, mestre, que prendreu mal!" era ni més ni menys que el jove professor de música de l'escola, un xicot d'una trentena encara no d'anys.

Agraït, com que encara tenia una estona, el vaig convidar a fer el vermut a la terrassa del cafè de davant del Liceu. I em sembla que va ser aleshores quan li vaig dir que havia de posar música, sí o sí, a alguns textos per fer-ne càntics per als nostres alumnes. Serien una mena de targeta de presentació sonora de la nostra proposta d'educació nova, proposta que volia en sintonia amb els temps moderns. El vaig avisar: "són cançons de guerra $i$ - $i$ això segur que no li agradarà- les tenim en castellà". I ii vaig recitar, perquè me'l sé de memòria, el poema pujat de to de l'ex-ministre canari federal, la futura cançó de les joguines. Feia així: ";Oh, patriotismo, negra falsedad, /fuente y origen de la autoridad! De insano origen, cual la propiedad, I nace solamente la desigualdad.

Os interrumpen en las lecciones, / ya las campanas, ya los tambores, ya las cornetas, ya los cañones. / ¡Hacen más ruido, los más innobles!"

Va arrufar d'entrada el nas i va dir que s'ho pensaria, que estava molt ocupat component, però el fet és que l'home no va trigar gaire temps a acceptar el meu encàrrec, que per cert li vaig pagar generosament, com corresponia fer-ho amb un jove professional autor de sarsueles com La dama d'Aragó o Ofèlia, estrenades a llocs de la ciutat com que no reparé en que desde la parte alta de la Rambla de Canaletes bajaba, por mi carril de peatones, a toda leche, un mozarrón ciclista con una gran cesta llena de flores en su portabultos.

¡Por suerte mía, alguien oportunamente me apartó en el momento preciso, ya que, de lo contrario, el choque con el transportista de dos ruedas habría sido de campeonato y muy preocupante, no os quepa dudas, para mi integridad física! Inmediatamente me di cuenta de que quien me había dicho gritando: "jojo, maestro, va a lastimarse!" era nada menos que el joven profesor de música de la escuela, un joven de aún no treinta años. Agradecido, y aprovechando que todavía tenía tiempo, lo invité a tomar un vermut en la terraza del café frente al Liceu.

Y me parece que fue entonces cuando le dije que tenía que poner música, sí o sí, a algunos textos para hacer himnos para nuestros estudiantes. Serían una especie de tarjeta de presentación sonora de nuestra nueva propuesta educativa, propuesta que quería en sintonía con los tiempos modernos. Le advertí: "Son canciones de guerra y -esto seguramente no será de su agrado- las tenemos en castellano". Y le recité de corrido, porque me lo sé de memoria, el poema subido de tono del exministro federal canario, la futura canción de los juguetes. Éste decía así: ";Oh, patriotismo, negra falsedad, /fuente y origen de la autoridad! De insano origen, cual la propiedad, I nace solamente la desigualdad. Os interrumpen en las lecciones, / y a las campanas, ya los tambores, ya las cornetas, ya los cañones. / ¡Hacen más ruido, los más innobles!"

Frunció el ceño y me dijo que lo pensaría, que estaba muy ocupado 
la Sala Mercè o el Teatre Principal, de Barcelona.

Em va estar parlant de la seva experiència com a ajudant del mestre Morera, gran amic de Santiago Rusiñol. Molts dels cantaires del seu gran cor eren treballadors, analfabets musicals la majoria i, uns quants, analfabets amb totes les de la llei. Assajaven dues vegades per setmana, els nois abans de sopar, els veterans a la nit. El mestre els exigia molt. Es van estrenar el 1896 al saló de l'Ateneu Barcelonès, em va explicar. Actuaven sovint al Cau Ferrat de Sitges..

I així és com, deu fer cosa de cinc anys, a tot estirar, a la meva editorial vam acabar publicant un seguit de sis cançons escolars, amb música del jove mestre de qui us parlo i acurats dibuixos modernistes, amb temes com el que us he transcrit o d'altres dedicats al matí o a la vida.... I a fe que se'ls sabien, aquests cants o himnes. la nostra canalla.

Sobretot la cançó de les joguines, que els nens interpretaven a tres veus. Sí, encara la tinc al cap... componiendo, pero lo cierto es que el hombre no tardó mucho en aceptar mi encargo, que por cierto le pagué generosamente, como correspondía hacerlo con un joven autor profesional de zarzuelas como La Señora de Aragón o Ophelia, estrenadas en lugares de la ciudad como la Sala Mercè o el Teatro Principal.

Me estuvo hablando de su experiencia como asistente del Maestro Morera, un gran amigo de Santiago Rusiñol. Muchos de los cantantes de su gran coro eran obreros, en su mayoría analfabetos en música y, algunos, analfabetos absolutos. Ensayaban dos veces por semana, los jóvenes antes de cenar, los mayores por la noche. El profesor les exigía mucho. Se estrenaron en 1896 en el salón del Ateneu Barcelonés, según que me contó. A menudo actuaban en Cau Ferrat en Sitges.

Y de este modo, hará a lo sumo unos cinco años, mi editorial acabó publicando una serie de seis canciones escolares, con música del joven profesor del que hablo y cuidadosos dibujos modernistas, con temas como el que transcribí u otros dedicados a motivos como "la mañana" o "la vida" ... Y doy fe que se los conocían bien, estos cantos o himnos, nuestros alumnos. Especialmente la canción de los juguetes, que los niños cantaban a tres voces. Sí, todavía lo tengo en mi cabeza...

\section{HISTORIA, FICCIÓN Y NOVELA HISTÓRICA}

Nos unimos, desde luego, a las muchas plumas que han subrayado en las últimas décadas la trascendencia de la narratividad en historia (WHITE,1973,1992), aunque no se trata, por nuestra parte, de una toma de posición fundamentalista al respecto, ya que un distanciamiento de sano 
relativismo y eclecticismo siempre es aconsejable, siguiendo la máxima aristotélica a que hacemos referencia en la conclusión de este artículo

En su momento White incidió en la "referencialidad" de la historia como género, "referencialidad" entendida como la cualidad distintiva de la construcción histórica, consistente en apuntar HACIA la realidad "de lo que sucedió", dando sentido a una serie de "datos" relativos a hechos ocurridos en el pasado (AURELL, 2006, p. 633).

En la recreación historiográfica Hayden White distingue diversos niveles: por un lado, la trama o forma literaria, por el otro, la "teoría histórica" implícita en la producción historiográfica y, finalmente, la intencionalidad práctica del historiador, algo así como su visión política y moral.

Analizar la trama desde el punto de la crítica literaria y lingüística le parece capital, como no dejan de señalar sus exegetas (AURELL, 2006), a veces incidiendo en auténticas perogrulladas como la afirmación de que "cualquier relato de esos acontecimientos (históricos) tiene una existencia exclusivamente lingüística", ya que, a fin de cuentas, cualquier disciplina científica tiene un sustrato lingüístico consubstancial. ¿O acaso se puede exponer un teorema matemático sin el meta-lenguaje pertinente?

Por su parte, la presencia (en la reconstrucción historiográfica) de una teoría histórica y de un fondo ideológico, implícitos ambos, asegura o certifica la subjetividad radical de la narrativa histórica.

Sin embargo, hay que matizar, al respecto, la idea de que todas las acciones del pasado sean siempre "narrativizaciones vividas". Hay, por ejemplo, "realidades administrativas" del pasado que nunca fueron "narradas" hasta el momento de su recuento (análisis) serial. Así pasa con, pongamos por caso, una serie administrativa de asociaciones ciudadanas inscritas o notificadas hallada en un archivo de la administración del estado, una serie administrativa que abarca, pongamos por caso, un período de ochenta años. Dicho recuento y análisis, de un interés retrospectivo enorme, fue la columna vertebral de uno de nuestros estudios (SOLÀ GUSSINYER, 1993) 3 .

En dicho estudio pusimos de manifiesto cómo, a través de una fuente como el Libro de Registro de Asociaciones de un Gobierno Civil y la documentación de archivo que fue generando durante décadas, el historiador social se habilita a fin de poder "narrar" la forma en que oficialmente

\footnotetext{
${ }^{3}$ Trabajo dividido en tres partes: la primera explica los objetivos del censo y los criterios utilizados para su preparación. El segundo incluye el censo analítico del movimiento asociativo en la ciudad de Barcelona, y el tercero consiste en el censo analítico de este movimiento en las comarcas de la demarcación provincial.
}

Rev. Iberoam. Patrim. Histórico-Educativo, Campinas (SP), v. 7, p. 1-21, e021003, 2021. 
se organizó la sociedad civil de un territorio (en este caso Barcelona y su hinterland) durante un período de tiempo crucial en la evolución del país, la que va desde la "normalización" del régimen monárquico restaurado hasta la "normalización” de la Dictadura franquista.

Así pues, en dicho estudio insistimos en la importancia de interpretar y sacar partido de estos datos administrativos, seriales. Sacar partido de ellos implica darles sentido, contextualizarlos e incardinarlos finalmente en una narrativa capaz, en el mejor de los casos, de neutralizar mitos. Podríamos decir, en último extremo, que historia no es solo narrar referenciando documentalmente de modo plausible, sino también aportar trabajosamente una base documental que se pueda referenciar para poder "narrar bien".

Ahora bien, en nuestro modo de ver, entre la reconstrucción histórica de hechos debidamente referenciados y de "contenido real" y la ficción pura y dura como ejercicio de imaginación (AURELL, 2006, p. 641), existiría la novela histórica rigurosa y seria.

Esta podría bien ser la tesis de fondo de la presente contribución: la "buena" novela histórica es útil y necesaria. ¿En qué sentido "buena, rigurosa y seria"?

En el sentido de que se atiene a criterios y no se resigna a vivir del mito. El mito y el contramito (demonización) de un personaje, movimiento o fenómeno social se ha expresado siempre y se expresa en forma literaria.

Cualquier comunidad humana, habida o por haber, vive de mitos (el "efecto Maradona" como paradigma). El mito genera ejemplos de altísimo contenido educativo. La Odisea griega o el Tirant lo Blanc, libro de caballerías best-seller medieval catalán, que inspiró el Quijote, lo muestran de forma fehaciente.

Y, como certeramente apunta el citado White, la historiografía occidental surge en el mundo clásico de un trasfondo literario, al intentar superar el discurso más arcaico del mito (AURELL, 2006, p. 643).

Pero las modas pasan y el auge del "giro lingüístico" auspiciado por White está en quiebra. Se ha llegado a señalar que "el relato y la narratividad en historiografía han derivado en una depauperización (empobrecimiento), en la práctica, del ejercicio del historiador al ir progresivamente reblandeciendo las fronteras entre ésta y la novela histórica" (VÁZQUEZ GESTAL, 2006, p. 243-244). 
A la vista está que con frecuencia la novela histórica conecta más con el lector, con un vasto auditorio, que el ensayo histórico erudito. Indudablemente, la novela histórica refuerza lazos de identidad entre el público lector. Una identidad basada en valores "educativo-sociales" mutantes, en evolución.

En nuestra novela histórica (SOLÀ GUSSINYER, 2020-2021, en prensa) uno de los problemas que se plantean es cómo hacer que nuestra sociedad entienda algo que hace ciento veinte años era casi "axiomático" entre la clase obrera: el "valor" de la solidaridad en la lucha de clases, un valor que no discutían ni la burguesía ni los trabajadores.

Aduzcamos otros ejemplos, referentes de la historia de la literatura o clásicos modernos: el best-seller novela histórica del siglo XV Tirant lo Blanc, actualmente libro de lectura (en fragmentos) de los escolares del área lingüística catalana. La obra refleja el cambio, la mutación en los valores educativo-sociales en una época de crisis, de tránsito al Renacimiento. Toda la obra de ficción tan exitosa en su momento y durante bastante tiempo muestra el desencanto frente a la decadencia de los valores de caballería y la reprobación hacia quienes no practican estas virtudes y se rigen por motivaciones espurias como la acumulación de riquezas. Implícitamente el héroe de la historia, el caballero Tirant, de escasa alcurnia, pero de grandes virtudes, es un gran modelo para la clase dominante.

La novela entra a fondo en el debate de la Baja Edad Media entre la preeminencia de las letras (la sabiduría, la ciencia) y las armas (los valores ligados a la destreza bélica, a la fuerza y a la valentía y audacia). Asimismo, el trágico y casi absurdo fin del superhéroe muestra su fragilidad y adquiere un significado catártico de primer orden.

Si de una novela de caballerías de éxito del ocaso de la Edad Media pasamos a un clásico contemporáneo de la pedagogía social, el ucraniano Anton Makarenko (1888-1939), hallamos lo mismo: la narrativa de ficción como instrumento sobresaliente de intervención pedagógica, el mensaje educativo revestido de excelencia narrativa, literaria (PADILLA ARROYO; TAYLOR FLORES, 2015, ver bibliografía al final).

No se olvide nunca, por otro lado, que, hasta la época clásica de la cultura griega, las grandes narraciones mitológicas en poesía eran la columna vertebral curricular, junto con la educación física y la música. 
Valores mutantes, según épocas y contextos culturales, que señalan identidades de grupo cambiantes. Lo cortés no quita lo valiente: se pueden seguir confeccionando biografías y narraciones, sin por ello dejar de

insistir en los mecanismos creados por un individuo o grupo social para poder llegar a reconocerse y ser reconocido con respecto al resto del conglomerado social. La identidad es lo que nos hace ser y ser reconocidos por los otros. Es lo que nos dota de especificidad y, al tiempo, lo que configura las piezas, o nudos, de la trama social, o red, en la que el ser humano habita. Una identidad que se transforma, que no es única ni unívoca. (VÁZQUEZ GESTAL, 2006, p. 248).

Los grupos sociales tienden a evitar la disonancia cognitiva y el conflicto de valores. No es poco lo que puede contribuir el hecho narrativo a consolidar identidades de grupo.

Por su parte, el discurso histórico narrativo persigue usualmente la objetividad, muestra lo sucedido como una cadena de acontecimientos "como si se narraran a sí mismos", y presenta lo narrado "como una totalidad coherente, completa, concluida, plena" (LA GRECA, s.d.). Fuentes como ésta señalan "la frustración de la clausura narrativa” y la "imposibilidad de completitud con relación a un curso externo de acontecimientos", así como "la prevención frente a la imposición de orden a lo relatado". Ni en historia ni en relatos de ficción suele haber un final claro o definitivo.

Pero el lector tiene un "deseo de interpretación sintética" a través de la "narrativización de lo real" (WHITE, 1987). Aun así, el relato no puede, no debe clausurar en falso, cerrar totalmente el significado de lo narrado, sino que hay que saber dejar "abierto e incierto el significado posible" (LA GRECA, s.d., aquí siguiendo a Barthes), dejando expedito el paso a "la discusión sobre el ser mismo del acontecer".

Un acontecer que somos capaces de representar, de recrear mediante la escritura, rompiendo a través de ésta el "silencio o, en algunos casos, el silenciamiento", sin caer en la tentación de concluir en falso.

\section{A VUELTAS CON UN EXPERIMENTO INTELECTUAL}

Esta reflexión sobre la narración en historia se enmarca, insistimos, en una experiencia reciente de re-escritura de una concatenación de sucesos de importancia para la historia cultural y educativa contemporánea.

Rev. Iberoam. Patrim. Histórico-Educativo, Campinas (SP), v. 7, p. 1-21, e021003, 2021. 
A saber, el impacto de la educación laica y racionalista en el tramo central de la Restauración Monárquica española (1874-1931).

La Escuela Moderna de Ferrer Guardia intentó materializar la pretensión de cambiar la sociedad a través de un plan de educación igualitaria, racional y libre. El intento se cerró en falso con la ejecución manu militari de su principal promotor. Tema éste del que tratan, a veces, los manuales y tratados de historia de la educación.

Como es sabido y conocido la historia de la educación como especialidad historiográfica se desenvuelve en muchos planos interconectados, que van desde la historia de la escuela a la interpretación del patrimonio educativo, desde el análisis de las ideas pedagógicas al estudio de las políticas educativas, desde lo formal en educación a lo informal, pasando por lo no formal, desde la detección e inventario de nuevas fuentes documentales a la exploración de las riquezas de las historias de vida.

Precisamente es sobre este último punto donde se centra la presente contribución, que pretende ofrecer elementos de reflexión acerca de los límites del género biográfico.

Nadie puede dudar a estas alturas de la utilidad histórico-educativa de las historias de vida y del método biográfico. Estas nos permiten, por ejemplo, documentar la represión de muchas iniciativas de educación democrática llevadas a cabo por regímenes autoritarios y dictaduras durante el dramático siglo XX.

Ahora bien, la reconstrucción biográfica tiene que llevarse a cabo, en nuestro entender, desde premisas críticas para con el acto narrativo. Estamos evocando en el presente artículo hasta qué punto ha podido crecer, desde los ochenta, la literatura teórica sobre el tema. Los debates y polémicas al respecto han abundado desde entonces hasta hoy. La biografía histórica es fruto de la labor del historiador biógrafo o del novelista bien documentado. Es importante tenerlo en cuenta. Si la historia tiene siempre una componente importante de subjetividad, en lo que concierne al cultivo del género biográfico, esta subjetividad es doble. Estamos frente a un cruce de subjetividades. Decimos "cruce", que no fusión.

El biógrafo tiene en el biografiado a su alter ego. Se produce hasta cierto punto un inevitable proceso de identificación y apropiación distanciada, que habría que distinguir de la apropiación acrítica y compulsiva de un personaje y de su circunstancia. 
Es importante ver la génesis de este seguimiento o apropiación. En la carrera investigadora de cualquier estudiante la inicial elección de personaje/ de tema de investigación es crucial. ¿Personaje, tema? En no pocas ocasiones el personaje objeto de estudio no ha sido elegido espontáneamente por el investigador principiante. En el caso concreto sacado aquí a colación el tema de estudio de la tesis (tesina era el nombre en el argot académico) de licenciatura y, posteriormente el de la tesis doctoral fueron propuestos por otras personas.

En el caso de la tesina, leída en la Universidad de Barcelona, un joven investigador nos propuso profundizar en el puritanismo británico y el movimiento radical de "levellers". Finalmente salió un trabajo sobre la filosofía de John Milton.

Inmediatamente surgió la búsqueda de tema de tesis doctoral. Aquí también la propuesta (consistente en estudiar la filosofía política del fundador de la Escuela Moderna) partió de dos directores de tesis de la Sorbona parisiense del área de conocimiento de la filosofía política y moral.

Repárese en que, por lo general, en la elección de tema pesa tanto la propia biografía y los conocimientos y experiencias previas como la intervención de la "fuente de autoridad" en forma de orientador, tutor o director de investigación.

No diremos que se trate de una "toma de partido" artificial o falsa, por el hecho de que detrás de ella esté la figura del orientador, tutor o director de tesis.

Pero sí podemos constatar una radical asimetría determinada por la experiencia y conocimiento acumulado del académico de oficio (o en camino de serlo), frente a la bisoñez y conocimiento incipiente, mayormente libresco, del principiante. El resultado de este proceso es que muchos estudiantes/ investigadores noveles se ven abocados o impelidos a optar por una dirección que marcará su futuro intelectual e incluso profesional.

En nuestro caso, la abundancia de información al respecto en bibliotecas como la Nacional de París y archivos como el del Instituto Municipal de Historia de Barcelona o el Instituto Internacional de Ciencias Sociales de Ámsterdam pronto dieron alas a una investigación, que entraba en un terreno de ruptura con el statu quo a principios de los setenta, a pocos años de la muerte del Dictador.

Antes del deceso de éste la investigación había progresado tanto que quien la llevaba a cabo hizo oídos sordos del parecer de un eminente historiador, Jordi Nadal (1929-2020), referente en historia económica (NADAL OLLER,1975) quien le dijo textualmente que no había nada que 
hacer, investigar y decir sobre el tema Ferrer/educación racionalista, que ya todo estaba dicho al respecto.

Una biografía es siempre una construcción intelectual basada en indicios, retazos y demás elementos documentales y patrimoniales al alcance. Podría decirse que cualquier reconstrucción historiográfica -en este caso en forma de biografía- es un montaje donde el relato articulado cuenta mucho. Un relato articulado a partir de referentes documentales contrastables y "objetivos".

El problema es que estos "referentes contrastables" informan, "hablan", solamente hasta cierto punto. Tomemos como ejemplo, la biografía de un educador de referencia como el que nos ocupa: ¿cómo llegar "al día a día” de la persona biografiada? ¿Cómo cubrir o superar importantes lagunas informativas? El historiador biógrafo hace forzosamente un ejercicio de empatía, de "meterse en la piel del otro", un "otro" que llega a ser una especie de "alter ego".

Pero ¿qué diferencia existe entre el relato historiográfico (biografía de educador, en este caso) y el relato de ficción novelesca?

El historiador que sigue trabajosamente el rastro de la vida y obra de un personaje, de un grupo humano o de una institución educativa, se acerca, aproxima o asimila al narrador de ficción en la medida que imprime una coherencia a su exposición, una coherencia cronológica y causal.

Pero el historiador de la educación metido a biógrafo tiene siempre las de perder con relación al novelista. Las ventajas de la ficción son obvias. De entrada, es innegable que la ficción da mayor libertad para asociar y coordinar.

Bien podría decirse que la perspectiva biográfica da un sentido humano a la historia y la hace más amena y comprensible, en la medida en que la biografía sintetiza, permite coordinar, enlazar retazos informativos con mucha más agilidad.

Donde el relato histórico-académico más solvente analiza, desmenuza y separa a efectos expositivos, la perspectiva biográfica une, ensambla, permite una visión más compactada y holística, lo cual sin duda ayuda a comprender mejor. De modo que el historiador, convertido en novelista de ocasión, penetra más íntimamente en el personaje y tiende puentes entre las inevitables lagunas documentales.

El historiador evita de entrada, por razones procedimentales básicas, juzgar, contaminar su exposición con juicios de valor personales. En cambio, el novelista en funciones puede introducir elementos de autocrítica, apropiados o inapropiados, en la mente o la pluma de su "alter ego". 
En última instancia, la regla de oro no debiera de ser otra, a nuestro juicio -y aquí es inevitable, casi un deber, mencionar al gran clásico europeo de la novela histórica Stefan Zweig, finado en Petrópolis, Brasil, el 22 de febrero de 1942- que conseguir un relato de ficción plausible, posible y coherente frente al relato de ficción fantasioso y deformador de la referencias documentales, que de todo hay en la viña del señor.

En este terreno se impone atender al salto cuantitativo y cualitativo que va de la audiencia ordinaria del historiador (el ámbito universitario, por regla general) y la audiencia del narrador (el público culto lector, en general).

El narrador novelista no puede fantasear ni inventar hasta el punto de cambiar y adulterar la trayectoria vital de un personaje, sino que su relato de ficción tiene que profundizar en lo posible y probable de una vida. La truculencia y sensacionalismo pueden en el mejor de los casos tener algún valor crematístico, pero muy poco calado cultural.

Seguramente tiene razón quien sentenció que, desde su aparición como género, la biografía tendió "a fijar modelos de hombres: ejemplares los unos y execrables los otros. Ilustres por sus acciones o abominables, según las tornas. En todo caso, ejemplaridad y biografía van unidas".

El mismo autor apunta la propensión de nacimiento del género biográfico al paralelismo, a establecer comparaciones entre trayectorias vitales. De este modo, la biografía (o derivaciones de ella, “elogios fúnebres, apologías, memorias, ataques...”) deviene “un elemento de juicio esencial para entender una época y una sociedad"'(CARO BAROJA,1986, p. 23 i s.).

Pues bien, el historiador que ejerce de narrador de ficción tiene que esforzarse en sortear el determinismo de la ejemplaridad, intentando alejarse de la "novela didáctica", de la literatura "con mensaje".

Aquí también hay que dar la razón al antropólogo vasco cuando parte de la necesidad de profundizar en las vivencias y pulsiones determinadas por la situación existencial de la persona biografiada.

Basándose en el concepto de biografía de Kant, Caro Baroja entiende "el género biográfico en sus variedades, como instrumento de investigación antropológica”. La perspectiva biográfica "nos da un punto de referencia esencial en la "medida" del hombre, bien considerado individualmente, bien como ser social e histórico". 
El polígrafo vasco concluye afirmando que "la biografía puede proporcionar imágenes coherentes o imágenes contradictorias: porque el hombre como «medida» de sí mismo es coherente, por un lado, incoherente y contradictorio por otro. El hombre está en una encrucijada que es su propia vida" (CARO BAROJA,1986, p. 34-35).

Precisamente este aspecto, el tratamiento de las contradicciones e incoherencias vitales, es uno de los puntos fuertes de la novela histórica. En nuestro ensayo de novela, por ejemplo, abordamos el contraste entre el principio de la coeducación de sexos, de que su protagonista hizo bandera, y su repetido fracaso en el trabajo en equipo con intelectuales y activistas del otro sexo. O el síndrome J.J. Rousseau ("desentenderse" de los hijos), a propósito de la relación del protagonista de la novela con su descendencia.

FIGURA 1: Retrato de la hija del protagonista, hacia 1910.

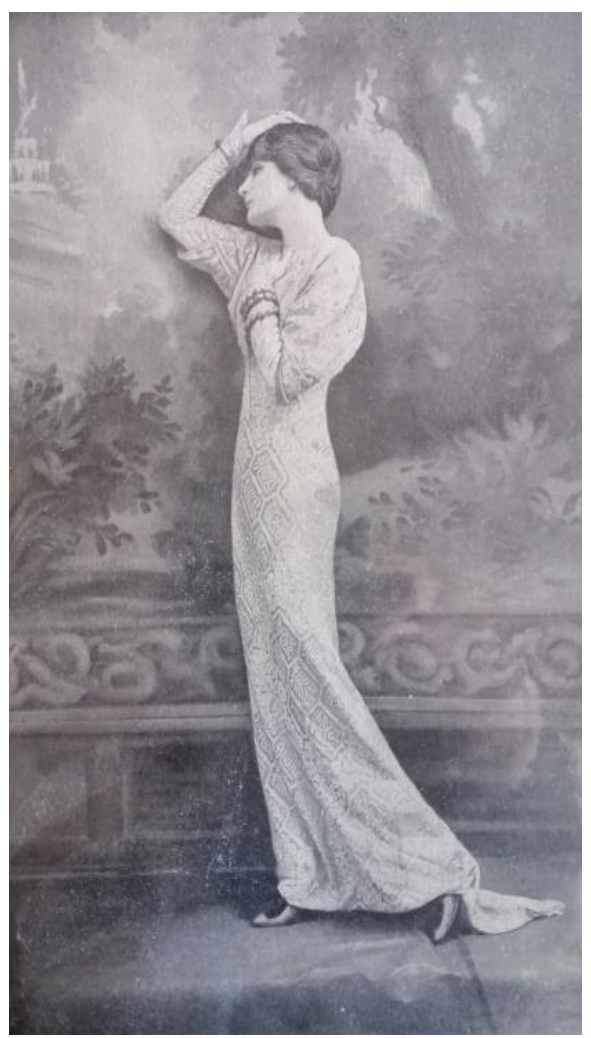

Fonte: archivo personal PSG. 


\section{CONCLUSIÓN}

Decir a modo de final que la presente reflexión saca partido de las lecciones de una experiencia vital durante el severo confinamiento (de marzo a mayo de 2020) en una urbe como Barcelona (pero que podría ser cualquier conurbación del ancho mundo) por la pandemia, para mostrarnos hasta qué punto la "verdad histórica" y el "sentido profundo" de un pasado que nos interpela pueden ser potenciados por la narrativa de ficción, más allá de la hojarasca teórica y el andamiaje documental de la producción académica ordinaria.

Nuestras notas pretenden profundizar en el siempre necesario debate metodológico y epistemológico sobre la profesión del historiador. Las especialidades sectoriales, como la historia de la educación, por ejemplo, no pueden ser ajenas a los replanteamientos epistemológicos de las últimas décadas.

Está claro que, entre los muchos "instrumentos" del oficio del historiador, debemos considerar múltiples abordajes, tanto la narración como la construcción de inspiración estructuralista, la que se inspira en principios del marxismo como en la lucha de clases y el método dialéctico, así como también las aportaciones basadas en la historia cuantitativa y serial, pasando por la historia social, la historia económica y hasta incluso la últimamente de moda "historia cultural”, aunque ésta en el fondo parece más bien un cajón de sastre metodológico donde todo cabe.

Un sano eclecticismo basado en la máxima de "in medio virtus" (libro segundo, capítulo IX, de ARISTÓTELES, 2001) es lo que siempre me ha parecido necesario aplicar al oficio de historiador. Se trata de evitar la denominada "historia de los acontecimientos", concepto puesto en circulación por François Simiand (1873-1935), en tanto que simple y desnudo relato cronológico de acontecimientos seleccionados a discreción (sin preocuparse demasiado por las causas y razones profundas del devenir histórico).

Superar el relato que yuxtapone acontecimientos (histoire événementielle) teniendo en cuenta -sin excederse tampoco- la línea de autores como Hayden White, quien, entre otros, ha desmenuzado de forma fructífera el nexo entre la historia y la ficción literaria. Esta corriente pone el acento en el denominado "giro lingüístico", punto de vista epistemológico según el cual la visión de la realidad presente y pasada depende del lenguaje de que nos servimos para describirla de modo

Rev. Iberoam. Patrim. Histórico-Educativo, Campinas (SP), v. 7, p. 1-21, e021003, 2021. 
inteligible, por lo que "el discurso de la Historia sería una construcción, un artificio, una suerte de impostura documentada sobre el pasado" (MARRERO HERNÁNDEZ, 2018).

\section{REFERENCIAS}

ARISTÓTELES. Ética a Nicómaco. Traducción, introducción y notas: José Luis Calvo Martínez Madrid: Alianza Editorial, 2001.

AURELL, J. Hayden White y la naturaleza narrativa de la historia. Anuario Filosófico, xxxix/3, p. $625-648,2006$.

BARTHES, R. El susurro del lenguaje. Barcelona: Paidós, 1987.

BARTHES, R. La aventura semiológica. Barcelona: Paidós, 1990.

BIERSACK, A. The new cultural history. Ed. Lynn Hunt. Berkeley: University of California Press, 1989.

BURKE, P. ¿Qué es la historia cultural?. Barcelona: Paidós Ibérica, 2008.

CARO BAROJA, J. Genero biográfico y Conocimiento Antropológico. Discurso Leído El Día 15 de junio de 1986... Madrid: Real Academia Española, 1986.

CARRARD, P. Poetics of the New History. French Historical Discourse from Braudel to Chartier. Baltimore/Londres: Johns Hopkins University Press, 1992.

GOODSON, I. F. Historias de vida del profesorado. Barcelona: Octaedro-Eub, 2004.

KOSELLECK, R. Futuro pasado. Para una semántica de los tiempos históricos. Barcelona: Paidós Básica, 1993.

LA GRECA, M. I. El valor de la narratividad en Hayden White: Crítica, ambivalencia y escritura de la historia. UBA-UNTREF-CONICET [en línia, 2020], s.d.

LA GRECA, M. I. Entre la ironía y el romance: pasado, presente y futuro de la filosofía de la historia narrativista. Páginas de Filosofía (Universidad Nacional del Comahue), 14 (17):22-48, 2013.

MARTORELL, J. Tirant lo Blanc. Barcelona: Proa, 1490, 2021, versión Màrius Serra.

MARRERO HERNÁNDEZ, M. El giro lingüístico y el debate sobre la historia como disciplina científica. 2018. Disponible: http://www.latrovaweb.com/el-giro-linguistico-y-el-debate-sobre-lahistoria-como-disciplina-cientifica/ (consulta 2020). 
MOMIGLIANO, A. The Rhetoric of History and the History of Rhetoric: On Hayden White's Tropes. In: SHAFFER, E. S. (ed.). Comparative Criticism. A Yearbook. Cambridge: Cambridge University Press, 1981.

NADAL OLLER, J. El fracaso de la revolución industrial en España, 1814-1913. Barcelona: Ariel, 1975.

PADILLA ARROYO, A.; TAYLOR FLORES, X. V. La literatura como recurso pedagógico en Antón S. Makarenko". Actas del XVIII Coloquio de Historia de la Educación: Arte, literatura y educación:161-170. Vic: Universitat de Vic-Universitat Central de Catalunya, 2015.

RICOEUR, P. Temps et récit. Paris: Éditions du Seuil, 1984.

SOLÀ GUSSINYER, P. Francisco Ferrer Guardia, activista social y mártir de la educación libre”. Barcelona, estudio inédito, 2018.

SOLÀ GUSSINYER, P. Història de l'Associacionisme català contemporani: Barcelona i comarques de la seva demarcació (1874-1966). Barcelona: Generalitat de Catalunya, 1993. 566 p.

SOLÀ GUSSINYER, P. Quadern de cel-la (apunts de darrera hora). Barcelona: Llop Roig, 20202021.

LA SAGRERA, Barcelona, primavera de 2020.

VÁZQUEZ GESTAL, P. ¿Qué le pasó al giro lingüístico? RILCE 22(2), p. 237-257, 2006 [en línea, 2020].

WHITE, H. V. Metahistory. The Historical Imagination in Nineteenth Century Europe. Baltimore \& Londres: Johns Hopkins Univesrity Press, vertida al español en 1992, 2001, Metahistoria. La imaginación histórica en la Europa del siglo XIX. México: FCE, 1973.

WHITE, H. V. The Content of the Form: Narrative Discourse and Historical Representation. Baltimore: Johns Hopkins University Press, 1987.

ZWEIG, S. Amerigo: La crònica d'un error històric. Barcelona: Edicions de 1984, 2015.

ZWEIG, S. Erasmo de Rotterdam. Barcelona: Editorial Juventud, 1937.

ZWEIG, S. María Antonieta. Barcelona: Editorial Juventud, 1934.

Recebido em: 28 de fevereiro de 2021

Aceito em: 05 de março de 2021 